\title{
Radiation consequences of hypothetical accidents associated with transportation of spent nuclear fuel of nuclear submarines aboard floating technical base
}

\author{
S. Bogatov, V. Kisselev, O. Sorokovikova and V. Vysotsky \\ Nuclear Safety Institute of Russian Academy of Science, 52 B.Tulskaya, \\ 115191 Moscow, Russia
}

\begin{abstract}
Reload of spent nuclear fuel of nuclear submarines and its subsequent transportation for reprocessing may be carried out by the vessel - floating technical base (FTB). Up to 4-5 reactor cores $\left(\sim 10^{16} \mathrm{~Bq}\right)$ can be taken aboard, transportation can occur for long distance. In case of the accidents with infringement of protective barriers, FTB may be a significant source of radiation hazard. Two hypothetical accidents associated with explosion and fire aboard and sinking the FTB are analyzed. In the first case a source term for the release and aerial radionuclide spreading out have been estimated, in second case radiation consequences have been estimated for water way taking into account remaining protective barriers. Main task of the assessments was radiation impact on population and environment at long distances from the source.
\end{abstract}

\section{INTRODUCTION}

Reload of spent nuclear fuel of nuclear submarines and its subsequent transportation for reprocessing may be carried out by the vessel - floating technical base (FTB). Up to 4-5 reactor cores can be taken aboard, transportation can occur for distance of dozens and thousands kilometers.

Spent nuclear fuel (SNF) is stored in four storage tanks in tight cases (up to 204 cases total, $\sim 10^{16} \mathrm{~Bq}$ ). Maximal volume of liquid radioactive waste (LRW) may be of $\sim 600 \mathrm{~m}^{3}\left(\sim 5 \cdot 10^{10} \mathrm{~Bq}\right.$ of ${ }^{137} \mathrm{Cs}$ and $\sim 3 \cdot 10^{10} \mathrm{~Bq}$ of ${ }^{90} \mathrm{Sr}$ ), solid radioactive waste (SRW) of $\sim 20 \mathrm{~m}^{3}$ in containers. Besides SNF, LRW and SRW there are spent filters resin and reactor control rods $\left(\sim 3 \cdot 10^{15} \mathrm{~Bq}\right.$ of $\left.{ }^{152,154} \mathrm{Eu}\right)$ aboard. In case of the accidents with infringement of protective barriers, FTB may occur to be a significant source of radiation hazard.

Maximal from viewpoint of expectable radiological consequences hypothetical accidents associated with jet fall, navigation accident (vessel collision) and sabotage were analyzed. All scenarios in pessimistic assumptions may cause explosion and/or fire and subsequent FTB sinking. Main task of the assessments was radiation impact on population and environment at long distances from the source. Main task of the assessments was radiation impact at long distances from the source.

\section{AERIAL RELEASE}

\subsection{Source term assessment for aerial release}

Probability of jet fall was assumed to be of $10^{-6}$ year $^{-1}$ for area of $10000 \mathrm{~m}^{2}$ [1]. For the spent nuclear fuel (SNF) storage plane area is of $\sim 11 \mathrm{~m}^{2}$ and appropriate probability equals to $\sim 10^{-9}$ year $^{-1}$.

Conservative assumptions have been done for aerial release combining dispersal of SNF due to internal explosion and release elevation due to large fire.

It was assumed that all fuel assemblies in the storage will be damaged (deformed), about $2 \%$ of SNF will be finely dispersed and subsequent release will occur due to thermal impact on the SNF from 
burning of jet fuel. Radionuclide release was assessed according to recommendations [2-4]. As a most pessimistic assumption following values were taken:

- fine dispersal of $2 \%$ of SNF in one storage;

- release of noble gases $(\mathrm{Xe}, \mathrm{Kr})$ is of $50 \%$ of total amount in one storage;

- release of I and Cs isotopes corresponds to $5 \%$.

Radionuclide content in the SNF was taken from [5].

Mechanism of detonation burning of $1 \mathrm{t}$ of jet fuel was assessed in [6]. In the model burning zone ("fire ball") was assumed as expanding sphere, at the moment of burning completion radius of the sphere is of $\sim 15 \mathrm{~m}$ and velocity of elevation is about $10-15 \mathrm{~m} / \mathrm{s}$. Maximal temperature inside "fire ball" may be of $\sim 3000^{\circ} \mathrm{C}$. "Fire ball" is fallowed by smoke column that separates from elevating "fire ball" at the height of $\sim 30 \mathrm{~m}$.

Due to its buoyancy "fire ball" containing hot gases and aerosols will go up and aside. Involvement of ambient air into the cloud occurs initially due to its relative movement, later due to atmospheric turbulence. In stratified atmosphere cloud buoyancy will vary due to density of air involved. In stable atmosphere cloud will stop when buoyancy equals zero, in unstable atmosphere height of the cloud can be very large (up to boundary atmospheric layer).

Distribution of radionuclide release between hot elevating cloud and smoke column depends on many circumstances. In present assessment it was taken that about a half of total release will associate with smoke except gaseous ${ }^{85} \mathrm{Kr}$ that will be totally involved into high temperature cloud which elevation height was calculated to be of $\sim 700 \mathrm{~m}$.

Smoke column in calculations was modeled by three point sources of similar activity located at the heights 10,20 and $30 \mathrm{~m}$.

\subsection{Radiological consequences expected for aerial release}

Calculations were performed for "dry" and "wet" (atmospheric precipitations during cloud propagation) sediments for three areas. The results of radiation consequences expected for severe accident due to aerial release are presented in Table 1 for several points. Calculations have been done by computer code "Nostradamus" [6].

Table 1. Main results of calculation of radiation consequences due to explosion and big fire on board of the FTB.

\begin{tabular}{|c|c|c|c|c|}
\hline \multirow{2}{*}{\multicolumn{2}{|c|}{$\begin{array}{c}\text { Parameter } \\
\text { Distance from the place of accident, } \mathrm{km}\end{array}$}} & \multicolumn{3}{|c|}{ Assessment } \\
\hline & & 1000 & 50 & 20 \\
\hline \multicolumn{2}{|c|}{ Time of cloud arrival, hour } & 25 & 3 & 1,25 \\
\hline \multicolumn{2}{|c|}{ Time of inhalation, hour } & 35 & 0,5 & 0,25 \\
\hline \multicolumn{2}{|c|}{ Effective inhalation dose, micro Sv } & 1,7 & 55 & 1400 \\
\hline \multirow{2}{*}{$\begin{array}{l}\text { Surface } \\
\text { contamination } \\
(\max .), \mathrm{Bq} / \mathrm{m}^{2}\end{array}$} & $\begin{array}{c}\text { "dry" } \\
\text { deposition }\end{array}$ & $3 \cdot 10^{4}$ & $3 \cdot 10^{4}$ & $1 \cdot 10^{6}$ \\
\hline & $\begin{array}{c}\text { "wet" } \\
\text { deposition }\end{array}$ & $1,8 \cdot 10^{5}$ & $1,8 \cdot 10^{5}$ & $2 \cdot 10^{6}$ \\
\hline \multirow{2}{*}{$\begin{array}{l}\text { Maximal effective } \\
\text { annual dose to } \\
\text { population, micro Sv }\end{array}$} & $\begin{array}{c}\text { "dry" } \\
\text { deposition }\end{array}$ & 60 & 60 & 1800 \\
\hline & $\begin{array}{c}\text { "wet" } \\
\text { deposition }\end{array}$ & 100 & 100 & 1800 \\
\hline
\end{tabular}

At the aerial release maximal annual effective dose equivalent to shore population at distances of $20 \ldots 1000 \mathrm{~km}$ varies from units of micro to units of milli Sievert. 


\section{MARINE RELEASE}

\subsection{Source term assessment for marine release}

Severe accident may occur due to collision of the FTB with another vessel followed by seal failure of the compartments containing big radionuclide amounts. The most severe accidents are expected when one of the colliding vessels has large amount of flammables aboard (e.g. one of the vessel is fuel tanker), and fire is big enough to encompass storage of radioactive waste or SNF. The similar scenario cannot be excluded if burning fuel is spilling over water surface around FTB.

It was assumed that fire is intensive to cause accelerated radionuclide release. Probability of such event may be assessed as a product of following probabilities:

- probability of collision for the voyage;

- probability that impacted vessel is the FTB;

- probability that colliding vessel damages storage of radioactive materials;

- probability of fire occurrence;

- probability of the collision and fire are severe enough to cause significant radionuclide release and FTB sinking.

Assessments made by recommendations of [7] give probability for such event $\sim 10^{-9}$ per FTB voyage.

To assess release of liquid radioactive waste (LRW) it was assumed instant release of LRW from coolant cleaning tank with maximal permissible activity. Further radionuclide release was assessed in framework of compartment model, including fallowing protective barriers: fuel matrix, cladding of the fuel, case for fuel assembly, storage tank and vessel shells. Appropriate time constants were assessed on the base of works [8-11].

It was neglected by the effect of pollution absorption and sedimentation with sea meal, though some assessment performed indicated that this mechanism can remove soluble contaminants from sea water with time constant of $\sim 10^{-1}$ year $^{-1}$, that is significantly faster that radionuclide penetration through remaining protective barriers.

Protective barriers assumed and prolonged radionuclide release obtained in framework of compartment model are illustrated in Figure 1.

\subsection{Radiological consequences expected for marine release}

Sea water pollution due to radionuclide release was assessed both for adjacent to sunken FTB area and for large water basins. For the first case Gaussian type model and IAEA model [12] were used, for the second one - compartment model and IAEA model [12]. Results for ${ }^{137} \mathrm{Cs}$ content in nearest to sunken vessel area are presented in Figure 2.

Both models give similar results. Plane at Figure 2a corresponds to reference level for ${ }^{137} \mathrm{Cs}$ in sea water $350 \mathrm{~Bq} / \mathrm{m}^{3}$ [13]. Hazardous area has dimensions of $\sim 700 \times 2500 \mathrm{~m}$, high activity concentration is restricted by radius of $\sim 500 \mathrm{~m}$.

Results of calculations of radionuclide content for large water basins are presented in Figure 3.

\subsection{Contaminant transport within upper turbulent layer of sea water}

Due to plume landing or LRW release the contaminant can be dispersed within surface layer of sea water. In northern conditions at high altitudes in summer the thickness of this layer may be of dozens meters. Coefficients of turbulent exchange lay within $10 \ldots 10^{4} \mathrm{~m}^{2} / \mathrm{s}$ (for atmosphere $-10^{5} \ldots 10^{7} \mathrm{~m}^{2} / \mathrm{s}$ ).

Preliminary assessment indicates that under pessimistic conditions relatively high radionuclide content exceeding reference levels may exist for a long (several months) time in the center of contamination spot. 


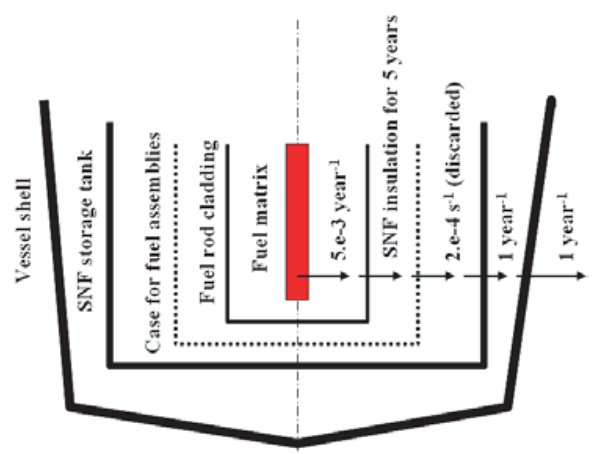

a)

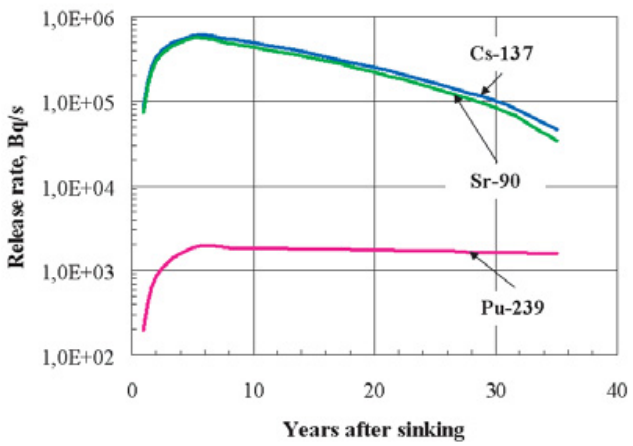

b)

Figure 1. Protective barriers (a) and the results of calculation of radionuclide release (b) from sunken FTB.

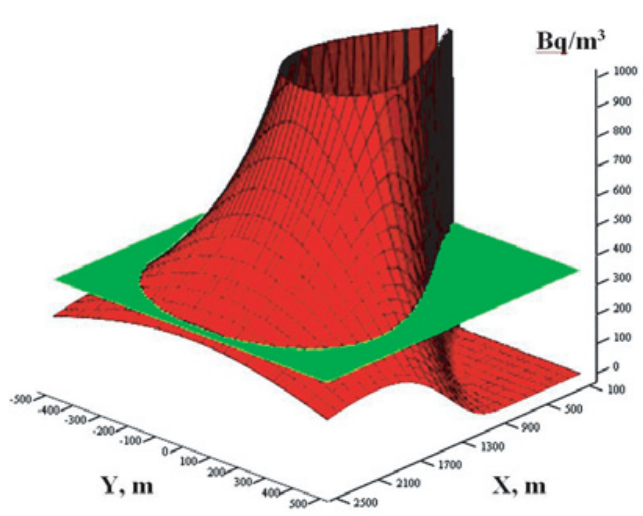

a)

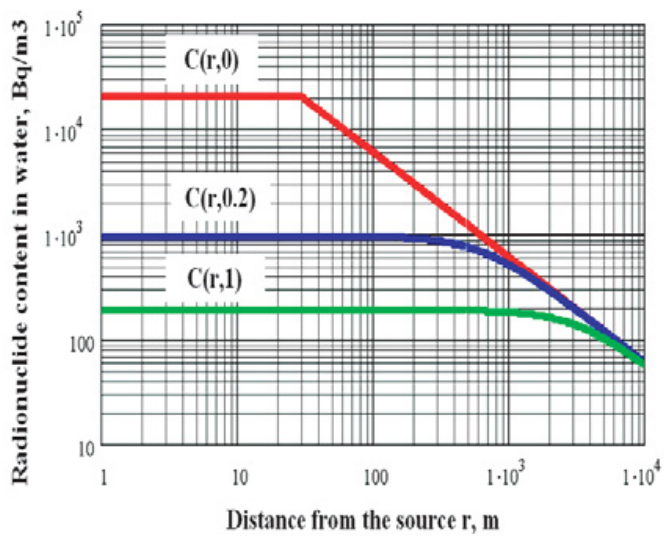

b)

Figure 2. Content of ${ }^{137} \mathrm{Cs}$ isotope near sunken FTB at release rate of $6 \cdot 10^{5} \mathrm{~Bq} / \mathrm{s}:$ a) Gaussian-like model, $1 \mathrm{~m}$ above the source; b) IAEA model [12]. $\mathrm{C}(\mathrm{r}, 0)$ - content at bottom level, $\mathrm{C}(\mathrm{r}, 0.2)$ - level of $20 \mathrm{~cm}$ above the source, $\mathrm{C}(\mathrm{r}, 1)$ - level $1 \mathrm{~m}$ above the source.

\section{CONCLUSION}

In case of aerial release permissible dose equivalent for population can be exceeded up to distance $\sim 30 \mathrm{~km}$ from the source.

Insignificant radiation impact is expected in average over the water area. Radionuclide content in fish muscles does not exceed hundredth parts of Becquerel per kilogram, expectable annular dose equivalent to critical population group is lesser than the impact due to global fallouts of atmospheric nuclear tests (tenth parts of $\mu \mathrm{Sv}$ ).

At the same time, in the vicinity of the sunken FTB extremely high radionuclide concentration in sea water and marine biota are expected. Death of all bottom biota is possible at the distance of hundred meters from the source.

Area of high (more than permissible) radionuclide concentrations in sea water can spread from sunken vessel for the distance of several kilometers. If contaminated area covers the places of long (several months) time residence of fish school, it is expected that a lot of species in fish catch will have 


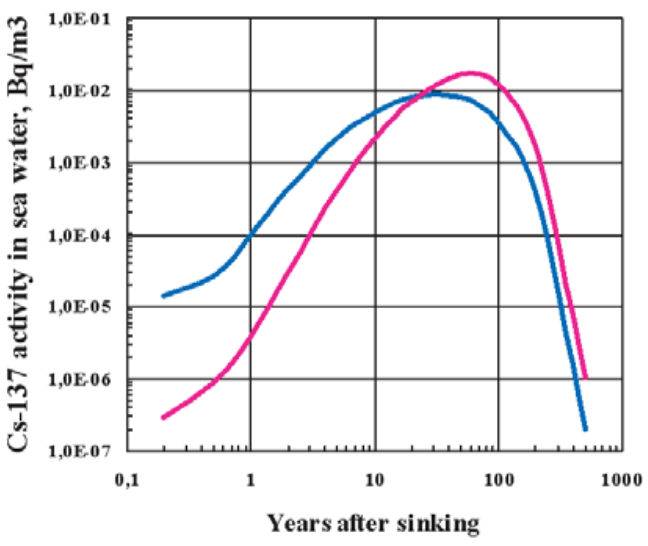

a)

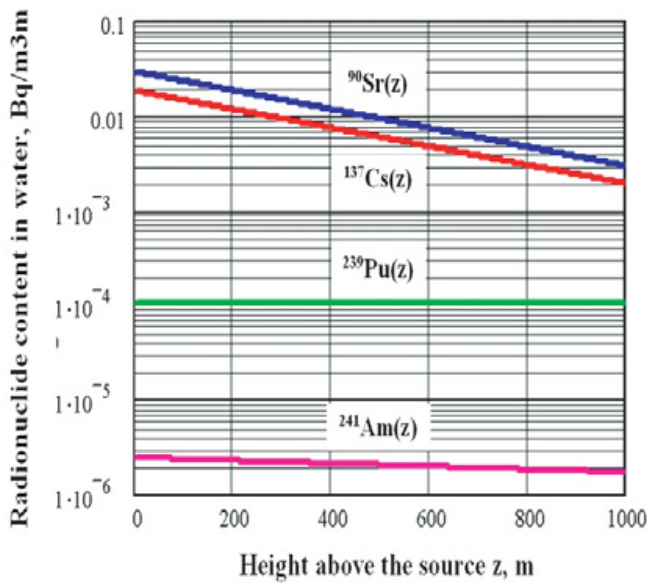

b)

Figure 3. Average radionuclide content in large water basins: a) dynamics of ${ }^{137} \mathrm{Cs}$ pollution (basin volumes are $3 \cdot 10^{16}$ and $4 \cdot 10^{15} \mathrm{~m}^{3}$ ) according to compartment model; b) radionuclide content along the depth of basin with volume of $\sim 3 \cdot 10^{17} \mathrm{~m}^{3}$ and depth of $4000 \mathrm{~m}$ according to IAEA model [12].

concentration of ${ }^{90} \mathrm{Sr}$ and ${ }^{137} \mathrm{Cs}$ about 10 and $100 \mathrm{~Bq} / \mathrm{kg}$ respectively. These levels are though two orders of magnitude lesser than permissible ones, but they are easily detectable. Appearance at the market such a "contaminated" fish can appreciably undermine competitiveness of definite fishery areas.

\section{References}

[1] General principles for design of nuclear power plants. Safety guidance N50-SG-D11. IAEA, Vienna (1988).

[2] Quintiery J.G., A Review of Experiments on the Airborn Release of Stimulated Radioactive Components from Fire. Fire Technology, Volume 34(4) (1998) pp. 307-324.

[3] Translations - safety codes and guides. GRS, Edition 7/83. October 1983.

[4] Banba T., Radionuclide release fractions from the spent nuclear fuel storage facilities under potential fire accident conditions in the Russian Far East Region". Internal RAD Project Report, IIASA, Laxenburg, Austria (2001).

[5] Studying Potential Environmental Consequences of the Maximum (Most Severe) Hypothetical Accident during Nuclear Submarine Utilization-Related Operations in the Kamchatka Peninsula (ATRP 1.3). Report on the First Part of the Project ATRP 1.3, (Contract \# 80169-2), NSI, Moscow (2004).

[6] Belikov V.V., Bogatov S.A., Gavrilov S.L et al. Assessment of radiological consequences for some hypothetical accidents for "DalRAO" facilities. Preprint of the NSI \#IBRAE-2002-05, Moscow (2002).

[7] Severity, probability and risk of accidents during maritime transport of radioactive material. IAEA-TECDOC-1231. IAEA, Vienna (2001).

[8] Marine corrosion. Reference book. Edited by M. Shumaher. Metallurgy, Moscow (1983).

[9] Ganul M.N., Kuchin N.L. and Sergeev I.V. Study of formation of radioactive contamination of sea water due to sinking of nuclear vessel in open sea. Atomic energy, Volume 81(4), (1966) pp. 282-287

[10] Dogedikov S.I., Juravkov A.M. and Zolotkov A.A., Corrosion stability of spent nuclear fuel in sea water. In: Proceedings of International scientific seminar of the USSR Nuclear Society in Murmansk, 24-28 September. Moscow (1991). 
[11] Nagakura T., Maki Y. and Tanaka N. Safety evaluation on transport of fuel at sea and test program on full scale cask in Japan, PATRAM'78, (1978).

[12] The oceanographic and radiological basis for the definition of high-level wastes unsutable for dumping at sea. IAEA, Vienna, $1984-51 \mathrm{p}$.

[13] Ganul M.N., Kuchin N.L., Sergeev I.V., et al. About reference concentrations of man-made radionuclides in sea water. Ecological chemistry, Volume 8(3), (1999) p. 197. 